\title{
Images of
}

Blood Research Educational Material

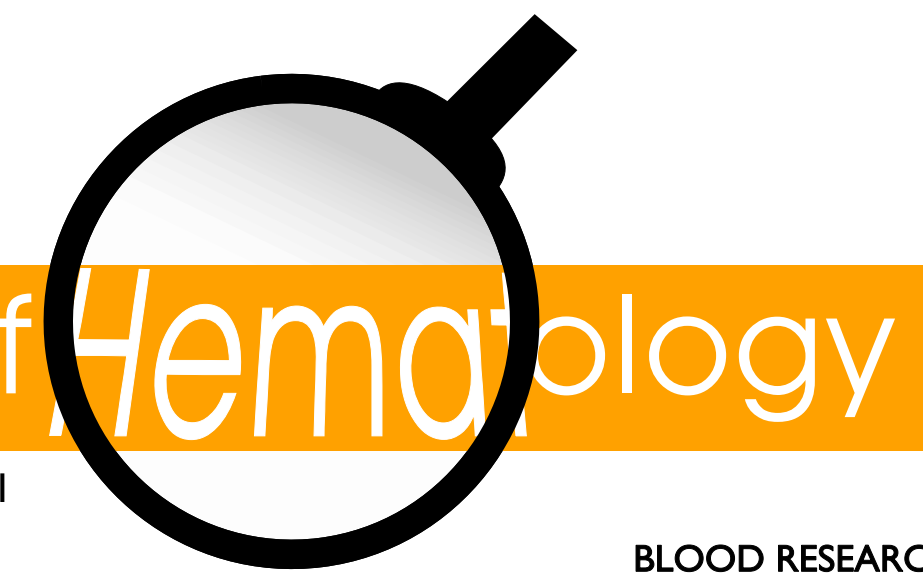

Volume $54 \cdot$ Number $3 \cdot$ September 2019

https://doi.org/10.5045/br.2019.54.3.162

\section{Chronicles of blood morphology associated with steroid use}

\author{
Kavita Gaur, Vandana Puri, Shailaja Shukla, Sunita Sharma \\ Department of Pathology, Lady Hardinge Medical College, New Delhi, India
}

Received on April 23, 2019; Revised on May 9, 2019; Accepted on May 27, 2019

Correspondence to Vandana Puri, M.D., Department of Pathology, Lady Hardinge Medical College, Shaheed Bhagat Singh Marg, New Delhi 110002, India, E-mail: vandanapuri201@gmail.com
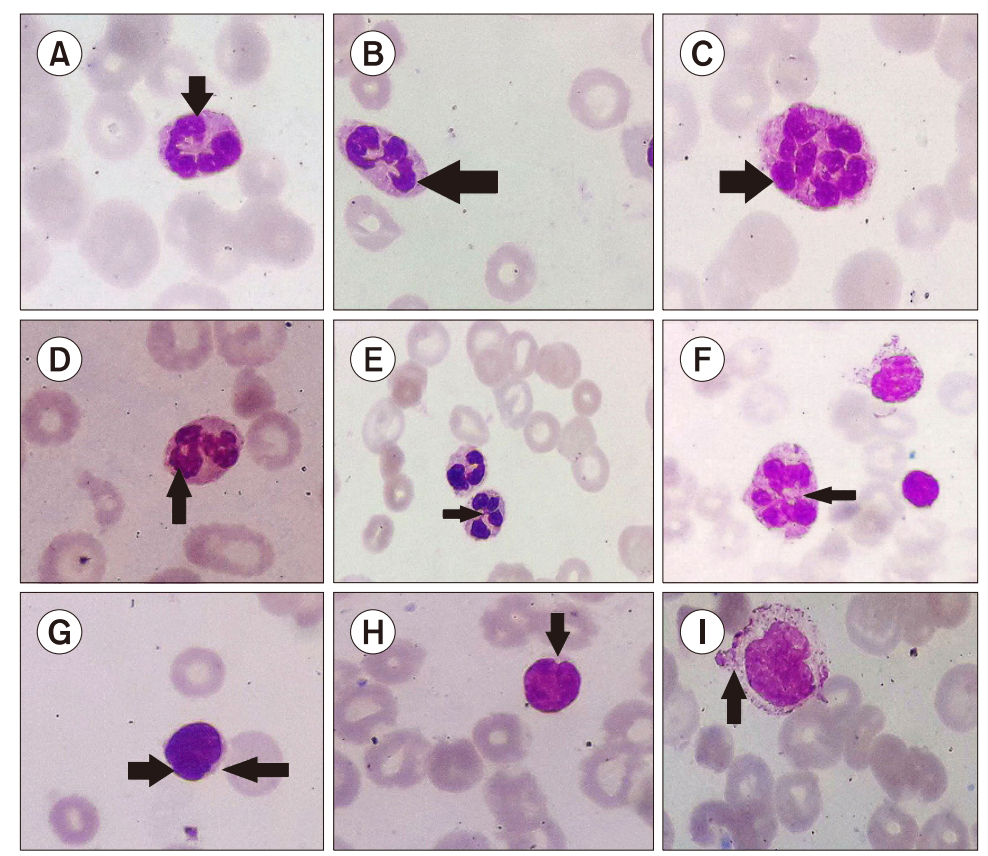

A 48-year-old man had jaundice for three months. Investigations revealed bicytopenia [hemoglobin, $4.5 \mathrm{~g} / \mathrm{dL}$; platelet, $30,000 / \mu \mathrm{L}$; white blood cell (WBC), $11,000 / \mu \mathrm{L}]$, unconjugated hyperbilirubinemia $(3.4 \mathrm{mg} / \mathrm{dL})$, and elevated hepatic transaminases (aspartate aminotransferase, $147 \mathrm{IU} / \mathrm{L}$; alanine aminotransferase, $297 \mathrm{IU} / \mathrm{L}$ ). The peripheral blood smear (PBS) revealed anisopoikilocytosis, macroovalocytes, polychromasia, nucleated red blood cells (RBCs), microspherocytes, and RBC agglutinates. The corrected reticulocyte count was 9.76\%. The direct Coomb's test was positive (4+). The indirect Coombs' test showed panagglutination. Other laboratory investigations were unremarkable. Fibroscan revealed advanced fibrosis $(2.0 \mathrm{KPa})$. For immune-mediated hemolysis, $50 \mathrm{mg}$ of prednisolone once a day was started.

On day 5, PBS showed unremarkable WBC and platelet morphology. On day 15, granulocyte nuclei showed projections (A), clubbing, "claw" shapes (B), hypo- and hypersegmentation (C), "lobar" rings, with a single lobe forming a ring (D), and thin intersegmental filaments (E, F). Indented nuclei ("pseudocleave") were seen in $10 \%$ of lymphocytes (G, H). Monocytes showed cytoplasmic fraying (I). Platelet morphology remained unremarkable. On day 21, RBC agglutination was absent. Nucleated RBCs, polychromasia, and granulocytic changes diminished. Hypersegmented neutrophils and intersegmental filaments persisted. Pseudocleaved lymphocytes decreased to $5 \%$. On day 31, some microspherocytes remained. Pseudocleaved lymphocytes were replaced by activated lymphocytes. Granulocytes showed occasional lobar rings. 